\title{
Review of Thymus Surgery, edited by Jiang Fan and Yuming Zhu- AME Publishing Company, Hong Kong, 2020
}

\author{
Ramón Rami-Porta ${ }^{1,2}$ \\ ${ }^{1}$ Department of Thoracic Surgery, Hospital Universitari Mútua Terrassa, University of Barcelona, Terrassa, Barcelona, Spain; ${ }^{2}$ Network of Centers \\ for Biomedical Research in Respiratory Diseases (CIBERES) Lung Cancer Group, Terrassa, Barcelona, Spain \\ Correspondence to: Ramón Rami-Porta, MD, PhD, FETCS. Department of Thoracic Surgery, Hospital Universitari Mútua Terrassa, Plaza Dr. Robert \\ 5, 08221 Terrassa, Barcelona, Spain. Email: rramip@yahoo.es.
}

Submitted Jan 17, 2021. Accepted for publication Jan 30, 2021.

doi: $10.21037 /$ jtd-2021-05

View this article at: http://dx.doi.org/10.21037/jtd-2021-05

At the peak of the Covid-19 pandemic in Spain, in April 2020, my friend, Dr. Diego González-Rivas, asked me to contribute a foreword for a book that was about to be published and of which he is an Associate Editor: Thymus Surgery. He sent to me all the chapters of the book, in a very advanced draft form, and gave me a tight deadline. Now, I am asked to write a review of the same book. I confess that this is a rather unusual experience to me-both to foreword and to review the same book-but, as I plunge into the task, I realize that, although interconnected, these are two very different activities. Unless one is given the necessary time, it is almost impossible to read the whole book to write a foreword. For the foreword, I certainly leafed through the chapters, checked for the multidisciplinary authorship, watched the figures, and read many sections of almost all chapters, so as to have a general idea of the scope and depth of the contents, and appreciate the impact that the book could have on the reader. My verdict was firm and clear: to trainees and certified thoracic surgeons, the book was "a well of information useful for their education and for performing their clinical and surgical practice". For the review, I have been given the electronic version of the published book, that is, its final format, and some more time to write it. The objectives of the review go beyond those of the foreword. The review must provide the reader with adequate information on its contents, its virtues and its limitations, if any. This is what I try to do in this text.

Although not divided into proper parts, when one reads the list of chapters, it is evident that the contents spans over three different sections. The first one contains six chapters on basic topics: the anatomy and physiology of the thymus, the pathologic classification, imaging and staging of thymic epithelial tumours (TETs), as well as the treatment of myasthenia gravis, with a separate chapter devoted to myasthenia crisis, which focuses the attention on the severity and relevance of this clinical condition. One chapter was added to the list I had received when I was invited to write the foreword: the contributions to the medical literature of the Chinese Alliance for Research in Thymomas (ChART). This chapter makes justice to the contribution of China to the furthering of knowledge in thymic diseases, but fails to mention the important contribution of ChART to the International Thymic Malignancies Interest Group (ITMIG), created in 2010 with the mission "to promote the advancement of clinical and basic science pertaining to thymic malignancies and related mediastinal conditions" (1). As a matter of fact, ChART was one of the institutions who collaborated with ITMIG in the creation of a common set of elements pertinent to the staging effort to develop an internationally acceptable tumour, node and metastasis (TNM) classification for TETs (2). True that the title of the chapter circumscribes its content, but it would have been a good place to underscore the contribution of ChART to the international staging endeavour.

The second section opens with a new chapter that was absent in the original contents of the book: Anesthetic management of myasthenia gravis. This chapter highlights the important peculiarities of the anaesthesia of these patients: when is best to operate, what anaesthetic and what muscle relaxant to use, and what antagonist of the relaxant to administer. This chapter precedes eight more on all possible approaches to the anterior mediastinum to remove the thymus and the thymomas. As it could not be otherwise in a book on surgery, this section is the largest. Starting with 
the progressively abandoned open procedures-median sternotomy, clamshell and hemi-clamshell, and the classic postero-lateral thoracotomy, that still are necessary for large or invasive tumours - the series of chapters continues with one on the generality of the many minimally invasive approaches to the thymus, as an introduction to the chapters that follow on the transcervical and subxiphoid approaches. This is more of a conceptual chapter than a chapter on surgical technique, and includes informative discussions on the effectiveness of minimally invasive surgery compared with that of open surgery; the optimal resection range and approach when performing minimally invasive techniques; and the comparison of video-assisted and robotic-assisted procedures. A chapter on the transcervical approach follows, describing well the indications and contraindications, the operative procedure and the outcomes, which are similar to those achieved by the more aggressive median sternotomy. The subxiphoid approach continues with three chapters, which show the predilection of our Chinese colleagues for this approach. The three chapters elaborate on slightly different variants of the procedure and are written by authors form one Italian and three Chinese hospitals. The three chapters emphasize the fact that this approach, alone or in combination with the elevation of the manubrium, offers a good view of both phrenic nerves, reaches the upper horns of the thymus, and avoids the intercostal spaces and the potential damage to the intercostal nerves, minimizing postoperative pain. The two final chapters of this section deal with robot-assisted thymectomy (RATS-thymectomy) done from both sides of the chest or from the subxiphoid approach; and with recurrent thymomas, a chapter that encompasses both the surgical and non-surgical treatment of recurrences. The three chapters on the subxiphoid approach and the one on RATS-thymectomy include short videos of the procedures that show the anatomic structures of the mediastinum and the range of exploration that can be reached through this approach.

The closing section of Thymus Surgery has three chapters on decision-making in thymic surgery, the comprehensive treatment of thymomas, and their biologic therapies. These chapters are a necessary complement to the surgical ones. Resection is the indicated therapy for many thymomas and poses little difficulties at the time of making treatment decisions, but invasive tumours, recurrent thymomas or thymic carcinomas are challenging clinical situations that require multidisciplinary assessment and a thoughtful therapeutic approach.

The honorary editor, Dr. Gening Jiang, and one of the editors, Dr. Jiang Fan, of Thymus Surgery concluded their prologue with an apology for having completed the book in haste. I was surprised when I first read their text and I wondered why a book, which is an educational tool to stay, had to be completed in a rush. I do not know the answer, but a close scrutiny of the book reveals that, given more time, the book could have been improved. Since they welcome comments, I venture to list a few that they may consider in future editions of the book. Firstly, the chapter on anatomy has no figures. A certified specialist may not need a drawing of the thymus, but those not so well versed on thymic surgery would have appreciated a simple scheme, for example, of the common variants of thymic veins and arteries, the identification, dissection and ligation of which are so important at the time of thymectomy to avoid bleeding. Secondly, in the chapter on pathologic classification and imaging, a few microphotographs of the main types of thymoma and some images of chest $\mathrm{X}$-rays, computed tomographies, magnetic resonances and positron emission tomographies-the imaging techniques discussed-would have enlivened the chapter and would have contributed to the better understanding of the text. Thirdly, in the chapter on staging, I miss a table with the T, the $\mathrm{N}$, and the $\mathrm{M}$ categories and their descriptors, as well as the stage grouping of the TETs. The authors quoted the correct reference where the reader can find this information, but a simple table would have been much appreciated. A book is a deposit of information, and information is what the reader expects to find. It is important to realize that the TNM classification of TETs included in the $8^{\text {th }}$ edition of the TNM classification of malignant tumours is the first one that has been accepted internationally and that appears in the staging manuals of the Union for International Cancer Control and the American Joint Committee on Cancer. No previous TNM proposals succeeded in doing so. Fourthly, among the surgical chapters, I miss a dedicated one on the video-assisted thoracoscopic surgery (VATS), uniportal and multiportal. The procedure is mentioned in the general chapter on minimally invasive surgery of the thymus, but the lack of a dedicated chapter may give the wrong impression that this approach is not utilized any longer. In fact, uni- and multiportal VATS for thymectomy are performed with good results $(3,4)$. Finally, Thymus Surgery is a book written by 21 Chinese and 1 Italian authors in English, therefore, a book intended for the international readership. For this readership, a chapter summarising the contributions of the ITMIG in the first decade of its activities would have been very informative. There are 
important recommendations aimed at the standardization of procedures that are not mentioned or depicted in the book: the handling of the specimens (5), the redefinition of the mediastinal compartments (6), and the proposed lymph node map (7), among others.

The above suggestions for improvement do not diminish the value of the book. The book is outstanding as it is. The chapters are well written, are relatively short, and well documented with adequate references. The format, in AME Publishing style, is elegant and the clear type setting makes it easy to read. All in all Thymus Surgery is an extraordinary asset for the dissemination of knowledge that will benefit both the doctors and their patients.

\section{Acknowledgments}

Funding: None.

\section{Footnote}

Provenance and Peer Review: This article was commissioned by the editorial office, Fournal of Thoracic Disease. The article did not undergo external peer review.

Conflicts of Interest: The author has completed the ICMJE uniform disclosure form (available at http://dx.doi. org/10.21037/jtd-2021-05). The author has no conflict of interest to declare.

Ethical Statement: The author is accountable for all aspects of the work in ensuring that questions related to the accuracy or integrity of any part of the work are appropriately investigated and resolved.

Open Access Statement: This is an Open Access article distributed in accordance with the Creative Commons

Cite this article as: Rami-Porta R. Review of Thymus Surgery, edited by Jiang Fan and Yuming Zhu-AME Publishing Company, Hong Kong, 2020. J Thorac Dis 2021;13(3):1869-1871. doi: $10.21037 /$ jtd-2021-05
Attribution-NonCommercial-NoDerivs 4.0 International License (CC BY-NC-ND 4.0), which permits the noncommercial replication and distribution of the article with the strict proviso that no changes or edits are made and the original work is properly cited (including links to both the formal publication through the relevant DOI and the license). See: https://creativecommons.org/licenses/by-nc-nd/4.0/.

\section{References}

1. Detterbeck F. International Thymic Malignancies Interest Group: a way forward. J Thorac Oncol 2010;5:S365-70.

2. Huang J, Ahmad U, Antonicelli A, et al. Development of the International Thymic Malignancy Interest Group international database: an unprecedented resource for the study of a rare group of tumors. J Thorac Oncol 2014;9:1573-8. Erratum in: J Thorac Oncol 2014;9:1804.

3. Refai M, Gonzalez-Rivas D, Guiducci GM, et al. Uniportal video-assisted thoracoscopic thymectomy: the glove-port with carbon dioxide insufflation. Gland Surg 2020;9:879-85.

4. Singh G, Glotzbach J, Costa J, et al. Minimally invasive radical thymectomy. Ann Cardiothorac Surg 2016;5:59-61.

5. Detterbeck FC, Moran C, Huang J, et al. Which way is up? Policies and procedures for surgeons and pathologists regarding resection specimens of thymic malignancy. J Thorac Oncol 2011;6:S1730-8.

6. Carter BW, Tomiyama N, Bhora FY, et al. A modern definition of mediastinal compartments. J Thorac Oncol 2014;9:S97-101.

7. Bhora FY, Chen DJ, Detterbeck FC, et al. The ITMIG/ IASLC Thymic Epithelial Tumors Staging Project: a proposed lymph node map for thymic epithelial tumors in the forthcoming 8 th edition of the TNM classification of malignant tumors. J Thorac Oncol 2014;9:S88-96. 